D.O.I: $10.3895 /$ gi.v10i1.1471

\title{
ROTAS SOLIDÁRIAS: UM ESTUDO DAS ROTAS DE COLETA DE MATERIAIS RECICLÁVEIS NUMA COOPERATIVA POPULAR DE COLETA E SELEÇÃO DE RECICLÁVEIS
}

\section{SOLIDARY ROUTES: A STUDY OF ROUTES OF COLLECTION OF RECYCLABLE MATERIALS IN A POPULAR COOPERATIVE OF RECYCLABLE}

\author{
Marcos Ricardo Rosa Georges \\ Pontifícia Universidade Católica de Campinas - São Paulo - Brasil \\ marcos.georges@puc-campinas.edu.br, marcos.georges@ hotmail.com
}

\begin{abstract}
Resumo
Este trabalho apresenta um estudo das rotas de coleta de materiais recicláveis realizada por uma cooperativa popular de coleta e seleção de recicláveis incubada pelo CRCA (Centro de Referência em Cooperativo e Associativismo) na cidade de Campinas. Esta cooperativa popular possui um caminhão que, diariamente, realiza dois itinerários - um no período matutino e outro no período vespertino - em busca de materiais recicláveis em aproximadamente 200 empresas, condomínios e outros estabelecimentos que destinam seus recicláveis a esta cooperativa popular. No entanto, as rotas percorridas pelo caminhão não se mostravam eficientes, sendo, em alguns casos, longas e demoradas e com baixo volume de material coletado. O estudo apresentado neste trabalho propõe novas rotas de coleta com maior eficiência econômica se comparado com as rotas anteriores. Este estudo consiste na comparação do custo total para realizar o itinerário e o valor coletado pelo caminhão neste itinerário, determinando quais itinerários são os mais rentáveis e quais são os menos rentáveis. Para os itinerários menos rentáveis foi feito uma reordenação dos pontos de coleta utilizando o problema do caixeiro viajante e foi recalculada a rentabilidades destas rotas. Uma breve revisão teórica sobre logística, roteirização de veículos e detalhes sobre o cálculo do custo do frete completam o artigo.
\end{abstract}

Palavras chave: logística empresarial; cadeias de suprimentos reversas; sustentabilidade; coleta e seleção de recicláveis; cooperativas populares; roteirização.

\section{Introdução}

A busca por uma sociedade sustentável se apresenta como o principal desafio da civilização atual, e neste contexto a reciclagem de materiais constitui uma atividade necessária para a sustentabilidade. Além da preocupação ambiental, a reciclagem de materiais também desperta interesse social, pois na maioria dos casos, a mão-de-obra empregada é tipicamente de pessoas excluídas que encontram uma ocupação em separar o que é re-aproveitável naquilo que foi descartado.

Atualmente, as cooperativas populares têm se mostrado com um dos principais agentes no 
processo de reciclagem dos materiais, atuando na coleta, separação, enfardamento e destinação do material reciclado aos recicladores para a conversão destes materiais.

Em Campinas existem 14 cooperativas de coleta e seleção de recicláveis reconhecidas pela prefeitura que, conjuntamente, processam 45 toneladas de lixo ao dia, o que representa apenas $2 \%$ das 900 toneladas diárias produzida pela cidade. Cidades como Curitiba e São Paulo reciclam, respectivamente, $25 \%$ e $10 \%$ do total produzido. Outra dificuldade enfrentada pelo município de Campinas é que apenas em $75 \%$ dos bairros e apenas uma vez por semana é feita a coleta do lixo reciclável pela empresa contratada pelo Departamento de Limpeza Urbana (DLU) do município (GUGLIELMINETTI, 2009).

O resultado deste pequeno percentual reciclado e da baixa freqüência de coleta feita pela prefeitura resulta num baixo volume de material para as 14 cooperativas de coleta e seleção de recicláveis processarem.

A pouca quantidade de material enviado às cooperativas acaba refletindo na renda dos cooperados. Aparecida de Fátima Assis, presidente da Cooperativa Antonio da Costa Santos, que fica no Jardim Satélite Íris 2, disse que tem faltado garrafas pet, papel, alumínio, papelão, entre outros. "Esta semana, eu tive que dispensar dois turnos porque não tinha material". O meu sonho é trabalhar com um turno à noite. Se a gente recebesse mais, o ganho seria melhor (GUGLIELMINETTI, 2009).

Devido a este fato, algumas cooperativas populares de coleta e seleção de recicláveis, sob a incubação do CRCA - Centro de Referência em Cooperativismo e Assistencialismo - adquiriram pequenos caminhões e firmaram parcerias com diferentes organizações e realizam, por conta própria, a coleta de material reciclável em complemento ao material fornecido pela coleta da prefeitura, minimizando o problema de baixo volume de material.

Este processo de coleta própria pelas cooperativas foi se consolidando, adquirindo novos parceiros que destinam seus materiais reciclados à cooperativa e diminuindo, gradativamente, a dependência destas cooperativas do material coletado pela prefeitura. Em 2009, a cooperativa popular de coleta e seleção de recicláveis RECICLAR, incubada pelo CRCA, coletou, por meios próprios, 78,97\% do total de material recebido, o que significa um volume anual equivalente a 763 toneladas de materiais recicláveis coletado por veículo próprio.

Porém, este alto percentual de material coletado por meios próprios tem suas desvantagens, pois, as cooperativas não possuem conhecimento e nem recursos para planejar rotas eficientes, tornando o processo de coleta própria oneroso para as cooperativas.

É neste contexto que este trabalho se apresenta, analisando o processo de coleta de material realizado pela cooperativa popular RECICLAR, incubada pelo CRCA, de modo a propor novas rotas de coleta com maior eficiência econômica, contribuindo para o aumento do rendimento mensal dos cooperados desta cooperativa popular. 


\section{Breve referencial teórico}

\subsection{A logística empresarial e a função transportes}

Ainda não foi possível precisar quando a Logística surgiu na história da civilização. Há diversos relatos e feitos históricos que instigam a pensar desde quando a logística se faz presente na civilização, no entanto, há um consenso de que a Logística se originou através das campanhas militares.

Souza (2002), afirma que a logística originou-se no século XVIII, no reinado de Luiz XIV, onde existia o posto de General de Lógis responsável pelo suprimento e pelo transporte do material bélico nas batalhas.

Já Kunrath (2007) afirma que a logística remete aos tempos bíblicos, quando os líderes militares daquela época já se utilizavam da logística, pois as guerras eram longas e distantes e eram necessários grandes e constantes deslocamentos de recursos para transportar tropas e armamentos. Era necessário planejamento e organização para a execução das tarefas de transporte, armazenagem e distribuição de equipamentos e suprimentos.

Dias (2005) afirma que o sistema logístico foi desenvolvido com o intuito de abastecer, transportar e alojar tropas, propiciando que os recursos certos estivessem no local certo e na hora certa. Este sistema operacional permitia que as campanhas militares fossem realizadas e contribuía para a vitória das tropas nos combates.

Foi somente no século XX que a logística passou a fazer parte do cotidiano das empresas, e foi somente após os anos oitenta que a logística adquiriu a sua concepção atual, como uma função empresarial orientada para o atendimento de níveis de serviço previamente estabelecidos.

Atualmente, o Council of Supply Chain Management Professional define logística empresarial como:

Logística, é parte da cadeia de suprimentos, que planeja, implementa, controla de modo eficiente e eficaz o fluxo, direto e reverso, e a armazenagem de bens, serviços e informações relativas entre o ponto de origem até o ponto de consumo de modo a atender os requisitos do cliente (CSCMP, 2009).

Outra definição de logística bastante precisa é fornecida por Christopher (2009):

Logística é o processo de gerenciamento estratégico da compra, do transporte e da armazenagem de matérias-primas, partes e produtos acabados (além dos fluxos de informações relacionados) por parte da organização e de seus canais de marketing, de tal modo que a lucratividade atual e futura seja maximizada mediante a entrega de encomendas com o menor custo associado.

Na visão de Ballou (2006), a Logística é entendida como uma função empresarial que tem por objetivo atender o cliente em um Nível de Serviço especificado, e para isso são necessárias tomadas de decisão em todos os níveis (estratégico, tático e operacional), nas três áreas que compõe 
a Logística: Transportes, Estoques e Localização. Esta visão da Logística apresentada por Ronald Ballou posiciona a função transporte como um subsistema logístico.

Nazário et al (2000) afirmam que a função transporte é uma das principais funções logísticas, além de representar a maior parcela dos custos logísticos na maioria das organizações, tem papel fundamental no desempenho de diversas dimensões do serviço ao cliente. Do ponto de vista de custos, representa, em média, cerca de $60 \%$ das despesas logísticas, o que em alguns casos pode significar duas ou três vezes o lucro de uma companhia, como é o caso, por exemplo, do setor de distribuição de combustíveis.

Ballou (2006) apresenta a função transporte como sendo constituída de diversas atividades a serem realizadas, são elas: a programação de veículos, a definição de rotas de entrega e coleta, a determinação do ponto de consolidação do embarque, a seleção de modal, a decisão de ter frota própria ou terceirizada, são alguns exemplos de decisões logísticas relacionadas à função transportes.

Naturalmente algumas destas decisões são pertinentes ao nível tático-estratégico, como a seleção de modal ou a decisão de ter frota própria ou terceirizada, por outro lado, decisões de programação de veículos, definição de rotas e escala de motoristas são decisões tipicamente operacionais.

\subsection{Roteirização de veículos}

O Problema de Roteirização de Veículos (do inglês VehicleRouting Problem) foi formulado pela primeira vez por Dantzig e Ramser em 1959 em um artigo intitulado "The truck dispatching problem" publicado na revista Management Science, a partir de uma generalização do Problema do Caixeiro Viajante (do inglês Traveler Salesman Problem) apresentado por M. Flood em um artigo homônimo publicado na revista Operations Research em 1956 (PILLAC et al, 2013).

A roteirização (ou roteamento) de veículos é uma atividade tipicamente operacional que tem o objetivo de determinar a seqüência de paradas que um veículo deverá realizar de modo a obter a menor distância total percorrida, ou o menor tempo de trajeto ou ainda o menor custo total.

Segundo Cunha (2000) o termo roteirização de veículos, embora não encontrado nos dicionários de língua portuguesa, é a forma que vem sendo utilizada como equivalente ao inglês “routing" (ou "routeing") para designar o processo para a determinação de um ou mais roteiros ou seqüências de paradas a serem cumpridos por veículos de uma frota, objetivando visitar um conjunto de pontos geograficamente dispersos, em locais pré-determinados, que necessitam de atendimento.

Eunomoto e Lima (2007) apresentam uma classificação para o problema de roteirização de veículos que os dividem em três categorias. Segundo estes autores, esta classificação foi feita 
inicialmente em 1983 por Bodin et al (apud EUNOMOTO E LIMA, 2007) e já tomada como referência por diversos autores. Estas categorias de problemas de roteirização apresentados por Eunomoto e Lima (2007) são:

\section{a) Problemas de roteirização pura}

São problemas espaciais que não consideram as variáveis temporais ou precedências entre as atividades para elaboração dos roteiros de coleta e/ou entrega. Em alguns casos tem-se apenas a restrição de comprimento máximo da rota. Nesse tipo de problema existe um conjunto de nós e/ou arcos para serem atendidos que formarão uma sequiência de locais (rota), buscando alcançar a minimização do custo total de transporte.

\section{b) Problemas de programação de veículos e tripulações}

Os problemas de programação podem ser considerados como problemas de roteirização com restrições adicionais relacionadas ao tempo, quando várias atividades precisam ser executadas. Este tipo de problema pode ser dividido em dois casos: Programação de veículos e Programação de tripulações. O foco do primeiro está na seqüência das atividades para os veículos no espaço e no tempo e do segundo na movimentação da tripulação no espaço e no tempo.

\section{c) Problemas de roteirização e programação}

Os problemas de roteirização e programação envolvem relações de precedência entre as atividades envolvidas e também restrições de janelas de tempo (horário de atendimento e outros). Podem ser considerados como uma combinação de problemas de roteirização e programação. São problemas que freqüentemente surgem na prática e representam aplicações do mundo real. Apresentam restrições mais realistas, onde cada parada pode ter volumes a serem coletados ou entregues. Uma importante variação desse problema é o Problema de roteirização e programação de veículos com janelas de tempo (PRPVJT), onde os pontos para atendimento têm uma ou mais janelas de tempo durante o qual o serviço pode ser executado.

Pillac et al (2013) apresenta uma taxonomia dos problemas de roterização de veículos interessante, definida a partir da qualidade da informação (deterministica ou estocástica) e do momento que a informação está disponível para se resolver o problema (antes ou durante). A Figura 1 apresenta a taxonomia proposta por PILLAC et al (2013). 
Figura 1 - Taxonomia dos problemas de roteirização de veículos

\begin{tabular}{|l|l|c|l|}
\cline { 3 - 4 } \multicolumn{2}{c|}{} & \multicolumn{2}{c|}{ Qualidade da Informação } \\
\cline { 3 - 4 } & $\begin{array}{c}\text { Entradas } \\
\text { Deterministicas }\end{array}$ & Entradas Estocásticas \\
\hline \multirow{2}{*}{$\begin{array}{l}\text { Evolução da } \\
\text { Informação }\end{array}$} & $\begin{array}{l}\text { Informação inserida com } \\
\text { antecedência }\end{array}$ & $\begin{array}{c}\text { Estático e } \\
\text { Deterministico }\end{array}$ & Estático e Estocastico \\
\cline { 2 - 4 } & $\begin{array}{l}\text { Informação inserida ao } \\
\text { logo do tempo }\end{array}$ & $\begin{array}{c}\text { Dinâmico e } \\
\text { Deterministico }\end{array}$ & Dinâmico e Estocástico \\
\hline
\end{tabular}

Fonte: Pillac et al, 2013

A dimensão da qualidade da informação está relacionada à presença de variabilidade nos dados do problema, ou seja, se a informação é determinística (sem variabilidade) ou estocástica (com variabilidade). Já a dimensão da evolução da informação se refere ao fato de se ter a informação com antecedência para se resolver o problema ou se a informação é atualizada ao longo do tempo, à medida que o veiculo executa a rota.

Problemas de roteirização de veículos com dados sem variabilidade e conhecidos com antecedência são classificados como problemas estáticos e determinísticos, ao passo que problemas com dados que apresentam variabilidade e são conhecidos ao longo do tempo são classificados como dinâmicos e estocásticos. Naturalmente, os problemas estáticos e determinísticos são os mais simples de serem resolvidos em comparação aos dinâmicos e estocásticos, mas, mesmo assim, exigi-se conhecimento matemático avançado para resolvê-los.

Outra taxonomia dos problemas de roteirização de veículos é apresentada por Eksioglu, Vural e Reisman (2009) num artigo intitulado "The vehicle routing problem: A taxonomic review". Neste artigo, além de uma pesquisa detalhada nas diferentes abordagens do problema de roteirização de veículo, os autores fizeram também um estudo bibliométrico de como a produção científica relacionada ao problema de roteirização de veículo evoluiu ao longo dos anos desde a década de 50, conforme a Figura 2 exibida a seguir mostra.

Figura 2 - Evolução da publicação científica sobre roteirização de veículos

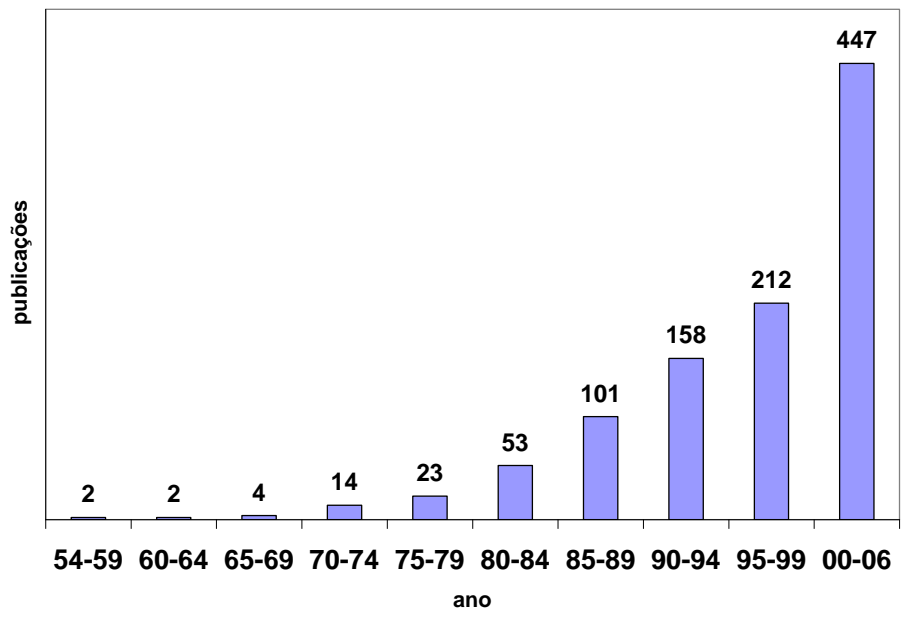

Fonte: Eksioglu et al, 2009 
A roteirização de veículos não é uma tarefa simples. Matematicamente é uma decisão de grande complexidade, pois o número de possíveis soluções é uma função exponencial do número de paradas. Este tipo de problema é conhecido como NP-difícil (NP-hard). Segundo Cunha (2000), isto significa que não é possível resolver até a otimalidade problemas reais pertencentes à classe NPdifíceis, conseqüentemente, os métodos de solução de todos os softwares e aplicativos comerciais encontrados no mercado para roteirização de veículos são heurísticos, isto é, não asseguram a obtenção da solução ótima do ponto de vista matemático.

Existem formulações clássicas da pesquisa operacional para resolver os problemas de roteirização nas três categorias acima. Para a primeira categoria há os problemas clássicos do caixeiro viajante e do carteiro chinês Goldbarg e Luna (2005), ambos resolvidos por programação linear, para as demais categorias existem extensões destes problemas de modo a incorporar variáveis e restrições que ampliam o escopo para as categorias seguintes.

Há também algumas heurísticas para se obter boas rotas, pois quando o problema possui um grande número de pontos de parada, este se torna demasiadamente exigente em termos de esforço computacional para ser resolvido por programação linear, sendo mais conveniente encontrar uma boa rota em pouco tempo que esperar muito para se ter uma rota ótima. São exemplos de métodos heurísticos o método da varredura e o método das economias de Clark e Wright (NOVAES, 2007).

Há ainda, vários outros fatores que aumentam a complexidade do problema, como variáveis relacionadas ao trânsito (congestionamentos, tráfego excessivo, lentidão, rodízios, etc.) ou então variáveis relacionadas com a malha viária (caminhos tortuosos, trechos não bidirecionais, zoneamento, etc.) ou ainda relacionadas ao cliente (horários de atendimento, condições especiais de embarque, etc.) e que quando consideradas, tornam o problema de determinação de rotas extremamente complexo e desafiador para o administrador ou engenheiro responsável pela logística.

Brejon e Belfiore (2006) fazem uma coleção ampla destes fatores relacionados aos problemas de roteirização de veículos e os agrupam em categorias que permitam uma melhor visualização, os agrupamentos sugeridos por Brejon e Belfiore (2006) são:

\section{Tipo de operação}

- coleta;

- entrega;

- coleta e entrega simultaneamente;

- coleta (ou entrega) com carga de retorno.

\section{Tipo de carga}

- única; 
- múltiplas cargas;

- necessidade de veículo especial para efetuar o transporte.

\section{Tipo de demanda}

- determinística;

- estocástica.

\section{Localização da demanda}

- demanda localizada somente em arcos;

- demanda localizada somente em nós;

- demanda localizada em arcos e nós.

\section{Restrições junto aos clientes}

- necessidade ou não de atender toda a demanda;

- existência de clientes com prioridade;

- existência de janelas de tempo;

- tempo máximo permitido para carga/descarga;

- necessidade ou restrição de serviço em algum dia específico da semana.

\section{Tamanho da frota}

- um único veículo;

- vários veículos.

\section{Tipo de frota}

- homogênea;

- heterogênea;

- veículos especiais (dedicados a um ou mais tipos específicos de carga).

\section{Localização dos veículos}

• em um único depósito;

- em vários depósitos.

\section{Restrições dos veículos}

- com relação à autonomia de cada veículo;

- com relação à quantidade de carga;

- com relação ao tipo de carga;

- com relação à operação de carga e descarga.

\section{Jornada de trabalho}


- duração;

- horário de almoço e outras interrupções;

- permissão para viagens com mais de um dia de duração.

\section{Número de tripulantes por veículo}

\section{Pagamento dos tripulantes}

- por jornada de trabalho;

- por produtividade;

- jornada e horas extras.

\section{Estrutura da rede}

- direcionada;

- não direcionada;

- mista;

- euclidiana.

\section{Duração de rotas}

- imposta, igual para todas as rotas;

- imposta, diferente para cada rota;

- não imposta.

\section{Restrições aos veículos}

- limite de peso do veículo;

- limite de altura, largura e comprimento do veículo;

- restrições de carga e descarga;

- número de rotas permitido por veículo.

\section{Outras restrições}

- necessidade de balanceamento da rota;

- existência de pontos de parada (descanso);

- proibição de contornos a esquerda por questões de segurança;

- obrigatoriedade de se utilizar rotas pré-determinadas.

\section{Estrutura de custos}

- custos variáveis;

- custos fixos.

\section{Objetivos}


- minimizar custos variáveis;

- minimizar custos fixos;

- minimizar soma de custos fixos e variáveis;

- minimizar duração das rotas;

- minimizar o número de veículos necessários;

- maximizar função de utilidade baseada no nível de serviço e/ou satisfação e/ou prioridades dos clientes;

- balanceamento de rotas;

- minimizar o uso de frota fretada.

No problema estudado neste artigo o tipo de operação é de coleta, o tipo da carga é única, a demanda é estocástica, localizada em nós e há restrição de se coletar em dias específicos da semana. A frota é composta de um único veículo e localização do depósito é única. Existe a restrição de capacidade do veículo e a jornada de trabalho é de oito horas com hora de almoço. A estrutura da rede é euclidiana e não direcionada, o tempo das rotas são diferentes e a estrutura de custos contém custos fixos e variáveis. O objetivo é verificar a viabilidade das rotas atualmente vigentes.

Quanto a classificação do tipo, o problema apresentado neste artigo enquadra-se no caso mais simples de problemas de roteirização de veículo, cujo objetivo é está relacionado a ao calculo dos custos totais, sendo necessário definir uma metodologia para calcular o custo do veículo e das rotas, o que é visto na seção a seguir.

\subsection{O custo do transporte rodoviário}

Segundo Maurício Pimenta Lima (2001) o custo do veículo é calculado a partir de itens de custeio que são fixos e outros que são variáveis. Por custos fixos entende-se aquele que não depende da distância percorrida, são eles: impostos, seguro, depreciação, salário do motorista, limpeza, custo de capital empenhado, entre outros.

Por outro lado, os custos variáveis são aqueles que dependem da distância percorrida, são eles: combustíveis, pneus, lubrificantes, manutenções, etc.

Para os custos fixos deve-se encontrar o quanto é custoso manter um veículo ao longo de um mês e depois calcular o custo da hora dividindo o custo mensal pelo número de horas trabalhadas no mês.

O custo de depreciação mensal é obtido subtraindo do valor de aquisição do veículo novo o valor do veículo usado e dividindo esta subtração pelo número de meses de depreciação, como na Equação 1 a seguir. 


$$
C_{\text {dep }}=\frac{V_{\text {aquisição }}-V_{\text {residual }}}{\mathrm{n}^{\mathrm{o}} \text { de meses }}
$$

O custo de capital é calculado aplicando-se ao valor pago pela aquisição do veículo a taxa básica do aplicada pelo mercado (em geral se usa a selic). Note que na Equação 2 a seguir a raiz duodécima é para transformar uma taxa anual em uma taxa mensal.

$$
C_{\text {oport }}=V_{\text {aquisição }}\left(\sqrt[12]{1+\text { taxa }_{\text {anual }}}-1\right)
$$

O custo de seguro do veículo, seguro obrigatório e impostos são calculados de modo simples, apenas dividindo o valor mensal por doze para se obter o quanto este item custa mensalmente.

$$
C_{I P V A / s e g}=\frac{\text { Valor anual }}{12}
$$

Para os custos variáveis deve-se encontra qual o custo por quilometro de cada item de custeio e depois somar para se obter o custo total por quilometro. Para alguns itens de custeio, basta dividir o custo gasto pela periodicidade com que este item de custeio ocorre, como no caso do custo de óleo lubrificante, onde o custo por quilometro é obtido dividindo o custo total gasto em uma troca de óleo pelo intervalo entre trocas (em geral a cada $10.000 \mathrm{~km}$ ).

$$
C_{\text {óleo }}=\frac{\text { preço }_{\text {litro }} . \text { capacidade }}{\text { intevalo entre trocas }}
$$

O custo do pneu é calculado de modo análogo, porém deve-se considerar a toda a vida útil de um pneu, incluindo-se suas recapagens, que em geral são duas. A Equação 5 a seguir apresenta o cálculo do custo do pneu.

$$
C_{\text {pneu }}=\frac{n_{\text {pneu }} \cdot\left(c_{\text {pneunovo }}+n_{\text {recapagens }} c_{\text {recapagem }}\right)}{\text { vida útil do pneu c/ recapagem }}
$$

Por fim, há o custo do combustível, calculado dividindo-se o preço do litro pelo rendimento do veículo, como na Equação 6 a seguir.

$$
C_{\text {combustive }}=\frac{\text { preço por litro }}{\text { rendimento }}
$$

Depois de obtido o custo de cada item consolida-se os dados numa tabela onde é dado o 
custo por quilometro rodado e o custo por hora de uso de um dado veículo. A Tabela 1 a seguir extraída de Pimenta Lima ilustra o cálculo do custo de um dado veículo.

Tabela 1 - Exemplo de cálculo do custo de um veículo

\begin{tabular}{|c|c|c|c|c|c|}
\hline \multicolumn{3}{|l|}{ mout de dados } & \multicolumn{3}{|c|}{ Outout } \\
\hline \multicolumn{3}{|l|}{ Custos da empresa } & \multicolumn{3}{|l|}{ Itens de custo fixo } \\
\hline $\begin{array}{l}\text { Salário do motorista } \\
\text { Horas de trab alhoi mês } \\
\text { Encargos e bene icios do moto rista } \\
\text { Taxa de oportunidade }\end{array}$ & 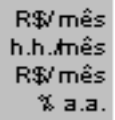 & $\begin{array}{r}750,00 \\
176 \\
562,50 \\
12 x\end{array}$ & $\begin{array}{l}\text { Depreciação } \\
\text { Rernuneraçẫo de capital } \\
\text { Muẫo de obra } \\
\text { IPVA/Seguro Obrigatório }\end{array}$ & 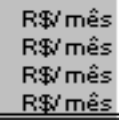 & $\begin{array}{r}833,33 \\
1.565,65 \\
1.312,50 \\
10000 \\
\end{array}$ \\
\hline Custos administr ativo & RFimês & 50000 & $\begin{array}{l}\text { CF } \\
\text { Custos administr ativo } \\
\end{array}$ & $\begin{array}{l}\text { Rףimês } \\
\text { Rqumês }\end{array}$ & $\begin{array}{r}3.811 .48 \\
50000 \\
\end{array}$ \\
\hline \multicolumn{3}{|l|}{ Dados do veículo } & \multirow[t]{2}{*}{ CF clcustos administrativos } & \multirow[t]{2}{*}{ Rqimês } & \multirow[t]{2}{*}{4.311 .48} \\
\hline Consumo de combustivel & Km/litro & 2,53 & & & \\
\hline Inte nu lo entre troca de óleo & $\mathrm{Km}$ & 10000 & \multicolumn{3}{|l|}{ Itens de custo variável } \\
\hline Litros de óleo por troca & litro & 30 & \multirow{4}{*}{$\begin{array}{l}\text { Combusti vel } \\
\text { Óleo } \\
\text { Pneu } \\
\text { Manutengâa } \\
\end{array}$} & $\mathrm{R} \$ \mathrm{Km}$ & 0,26 \\
\hline Número de pneus & & 18 & & $\mathrm{R} F \mathrm{Km}$ & 0,01 \\
\hline Inte na lo entre troca de pneu/recapagem & $\mathrm{Km}$ & 80000 & & $\mathrm{R} \$ \mathrm{Km}$ & 0,07 \\
\hline Número de recapagens & & 2 & & Rq Km & 0,13 \\
\hline Custos de manutenção & $\mathrm{R} \$ \mathrm{Km}$ & 0.13 & \multirow[t]{2}{*}{ Custo variável } & \multirow[t]{2}{*}{$\mathrm{R} \mathrm{W}^{\prime} \mathrm{Km}$} & \multirow[t]{2}{*}{0.47} \\
\hline \multirow[t]{2}{*}{ Inte nu lo entre lub rificaçốes } & $\mathrm{Km}$ & 2000 & & & \\
\hline & & & \multirow{2}{*}{$\begin{array}{l}\text { Custos fixos [R\$/hora] } \\
\text { Custos variáveis [R\$/ km] }\end{array}$} & \multirow{2}{*}{$\begin{array}{r}\mathrm{R} \$ \text { /hora } \\
\mathrm{R} \$ / \mathrm{km}\end{array}$} & \multirow{2}{*}{$\begin{array}{r}24,50 \\
0,47 \\
\end{array}$} \\
\hline \multicolumn{3}{|l|}{ Dados de meroado } & & & \\
\hline $\begin{array}{l}\text { Valor de aquisiçâo do veículo } \\
\text { Wda útil do veiculo }\end{array}$ & $\begin{array}{r}\mathrm{R} \$ \\
\text { meses }\end{array}$ & $\begin{array}{r}165000 \\
120\end{array}$ & & & \\
\hline Valor re sidual do veículo & $\mathrm{R} \Phi$ & 65000 & & & \\
\hline Preço do óleo & $\mathrm{R} q^{\prime}$ litro & 2,7 & & & \\
\hline Pre ço do combustivel & R $\mathcal{F}^{\prime}$ litro & 0.65 & & & \\
\hline Preço do pneu & $\mathrm{R} \Phi$ & 620 & & & \\
\hline Preço da recapagem & & 180 & & & \\
\hline IPVASSeguro Obrigatório & REvino & 1200 & & & \\
\hline
\end{tabular}

Fonte: Lima, M.P.

\section{Metodologia}

Trata-se de uma pesquisa aplicada cujo procedimento principal adotado foi a pesquisa documental nos registros existentes na cooperativa popular RECICLAR localizada no município de Campinas.

Com base nos estudos dos registros de itinerário dos veículos, foi possível conhecer detalhadamente as rotas percorridas em cada um dos dias da semana. Informações como número de pontos de coleta, a localização destes pontos, a distância total percorrida e o tempo total de trajeto puderam ser obtidos a partir deste registro dos itinerários percorridos.

Outro registro pesquisado foi o registro de recebimento de material, onde conta a quantidade de material coletado em cada dia da semana, podendo conhecer a quantidade média coleta por rota.

Por fim, utilizou uma metodologia de cálculo do custo do transporte rodoviário apresentado por Maurício Pimenta Lima (FLEURY et al, 2001) e se chegou ao valor do custo por hora e por quilometro percorrido pelo veículo.

De posse do valor médio da tonelada de material vendido pela cooperativa, já foi estudado cada uma das rotas e se chegou à conclusão de quais rotas são mais rentáveis e quais rotas precisam ser repensadas por não "valer a viagem”.

Os resultados desta análise estão apresentados a seguir, assim como o cálculo do custo do veículo usado na cooperativa. 


\section{Análise dos resultados}

\subsection{Caracterização da função logística}

A cooperativa popular RECICLAR e uma das oito cooperativas populares de coleta e seleção de recicláveis incubadas pelo CRCA que se organizam em rede e formam uma verdadeira cadeia de suprimentos reversa, coletando materiais em diversos pontos cidade e os processando até serem vendidos a grandes recicladores que os colocam novamente no mercado. A Figura 3 a seguir ilustra esta cadeia de suprimentos.

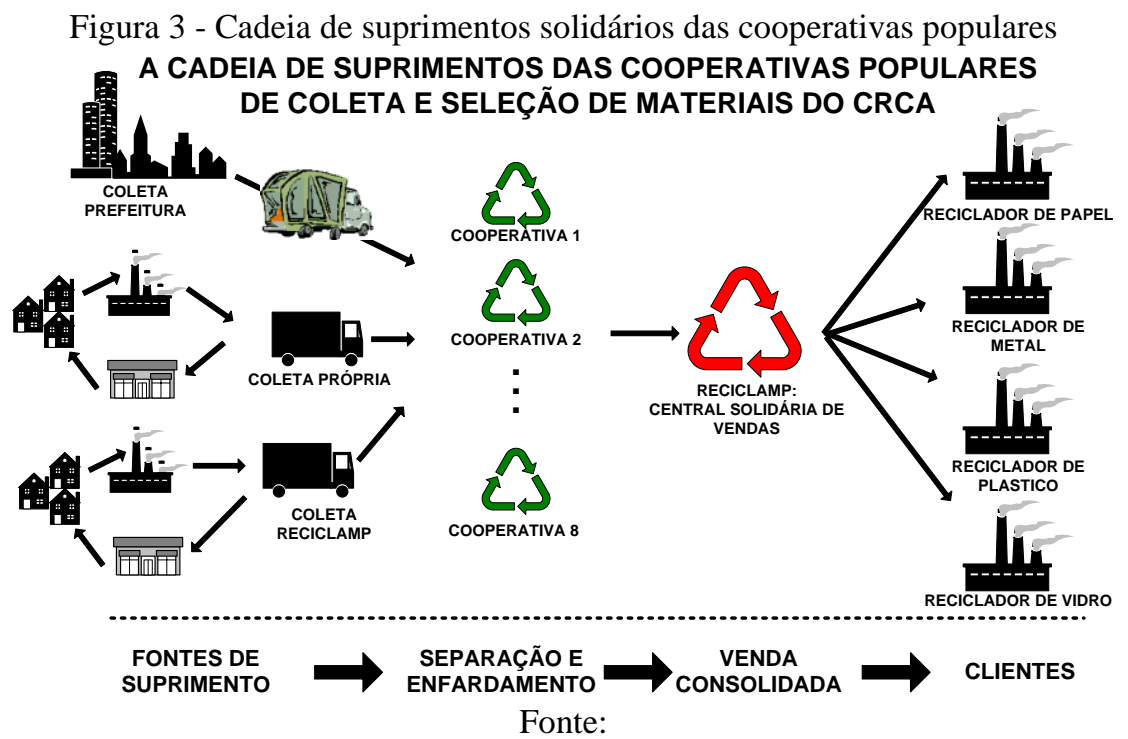

As fontes de suprimentos compreendem as empresas públicas e privadas onde as cooperativas fazem a coleta do material e a empresa de limpeza urbana contratada pelo município que faz a entrega da coleta seletiva. As cooperativas são o elo seguinte desta cadeia que separam e enfardam o material. Atualmente são oito cooperativas atuando conjuntamente nesta cadeia de suprimentos, sendo uma delas a cooperativa RECICLAR, local onde se desenvolveu o estudo das rotas apresentado a seguir.

A reciclamp é uma cooperativa de cooperativas que consolida a produção e faz a venda conjunta, ganhando volume e poder de barganha e eliminando a figura do aparista e vendendo diretamente aos recicladores, o último elo desta cadeia de suprimentos.

As fontes de suprimentos podem ser classificadas em três grupos distintos, o primeiro grupo é denominado de "Coleta Prefeitura" e origina-se da empresa de limpeza urbana no município de Campinas e representa 53,17\% do material recebido no ano de 2008.

O segundo grupo das fontes de suprimentos é denominado "Coleta Própria" e congrega grande variedade de estabelecimentos, como: indústrias, condomínios residenciais, shoppings, bancos, universidades, empresas públicas entre outros. Este grupo contém cerca de 200 locais onde os caminhões fazem a coleta, em geral, uma vez por semana, e que em 2008 totalizou 1.598 
tonalizadas, ou 37,59\%. A coleta própria é assim chamada porque é coletada pelos caminhões das próprias cooperativas, no entanto, nem todas as cooperativas realizam a coleta própria, só há 3 cooperativas que possuem caminhão. Nestas cooperativas, o material proveniente da coleta própria representa cerca de $70 \%$, chegando a quase $80 \%$ no caso da cooperativa RECICLAR.

O terceiro grupo é denominado "Coleta Reciclamp", pois é feita pelos caminhões pertencentes à Reciclamp, que coletam material em quatro locais: REPLAN, centro de distribuição dos correios, um shopping e um condomínio de empresas. Este grupo representa 9,25\% do total coletado em 2008. Somadas, as três fontes de suprimentos forneceram em 2008 um total de 4.250 toneladas de material às cooperativas populares pertencentes a esta cadeia de suprimento.

O estudo das rotas de coleta se deu no segundo grupo "coleta própria", mais especificamente em uma das três cooperativas populares que possui caminhão próprio, cujo detalhamento das rotas durante a semana está detalhado na seção seguinte.

\subsection{Caracterização das rotas de coleta}

As rotas de coleta de materiais recicláveis na cooperativa RECICLAR são preestabelecidas, havendo duas rotas de coleta para cada dia da semana, sendo uma para a manhã e uma o período vespertino. O detalhamento destes itinerários é feito a seguir.

Na segunda-feira de manhã o caminhão vai até um único ponto e retorna a cooperativa. Trata-se de uma grande indústria do segmento farmacêutico, que sozinha é capaz de preencher a gaiola do veículo usado para a coleta dos materiais recicláveis doados por esta. Nesta manhã de segunda-feira o caminhão percorre em média $74 \mathrm{~km}$, coleta em média $1745 \mathrm{~kg}$ e leva em média 04h56min para realizar o percurso. Na segunda-feira a tarde o caminhão faz a coleta em oito condomínios residenciais, percorrendo em média $25 \mathrm{~km}$, coletando em média $1180 \mathrm{~kg}$ e levando 3:30h em média.

Na terça-feira pela manhã o caminhão coleta material em 15 pontos, entre bancos, empresas e escola. Percorre uma média de $47 \mathrm{~km}$, coleta em média $1383 \mathrm{~kg}$ e demora cerca de $05 \mathrm{~h} 31 \mathrm{~min}$. para realizar o percurso (em média). $\mathrm{Na}$ terça-feira a tarde o caminhão passa por 22 estabelecimentos, percorre uma média de $20 \mathrm{~km}$, coleta cerca de $1047 \mathrm{~kg}$ e demora cerca de 3:15h. (valores médios).

Na quarta-feira pela manhã o caminhão passa por 29 estabelecimentos, percorre uma média de $27 \mathrm{~km}$, coleta uma média de $1650 \mathrm{~kg}$ e demora uma média de 05h30min para fazer todo o percurso. Na quarta-feira pela tarde o caminhão passa por 13 estabelecimentos, percorre uma média de $23 \mathrm{~km}$, coleta uma média de $798 \mathrm{~kg}$ e demora uma média de 3:14h para fazer todo o percurso.

Na quinta-feira pela manhã o caminhão passa por somente 4 estabelecimentos, percorre uma média de $46 \mathrm{~km}$, coleta uma média de $2527 \mathrm{~kg}$ e demora uma média de 5:50h para fazer todo o percurso. Na quinta-feira pela tarde o caminhão passa por 18 pontos, na maioria residências, 
percorre uma média de $29 \mathrm{~km}$, coleta uma média de $673 \mathrm{~kg}$ e demora uma média de 3:36h para fazer todo o percurso.

Na sexta-feira pela manhã o caminhão passa por 24 pontos, condomínios residênciais em maior parte, percorre uma média de $28 \mathrm{~km}$, coleta uma média de $1633 \mathrm{~kg}$ e demora uma média de 5:52h para fazer todo o percurso. Na sexta-feira pela tarde o caminhão passa por 13 pontos, percorre uma média de $17 \mathrm{~km}$, coleta uma média de $807 \mathrm{~kg}$ e demora uma média de 3:19h para fazer todo o percurso.

No sábado o caminhão passa por 35 pontos, em maioria residências e condomínios próximos entre si, percorre uma média de $17 \mathrm{~km}$, coleta uma média de $1313 \mathrm{~kg}$ e demora uma média de 4:24h para fazer todo o percurso.

Ao todo são coletados materiais recicláveis em 182 pontos pela cidade, percorrendo-se uma média de $353 \mathrm{~km}$, coletando um volume médio semanal $14.756 \mathrm{~kg}$ e levando-se, em média, 48h57min de trabalho durante a semana. A Figura 4 a seguir traz um gráfico que mostra a disposição geográfica dos pontos de coleta desta cooperativa.

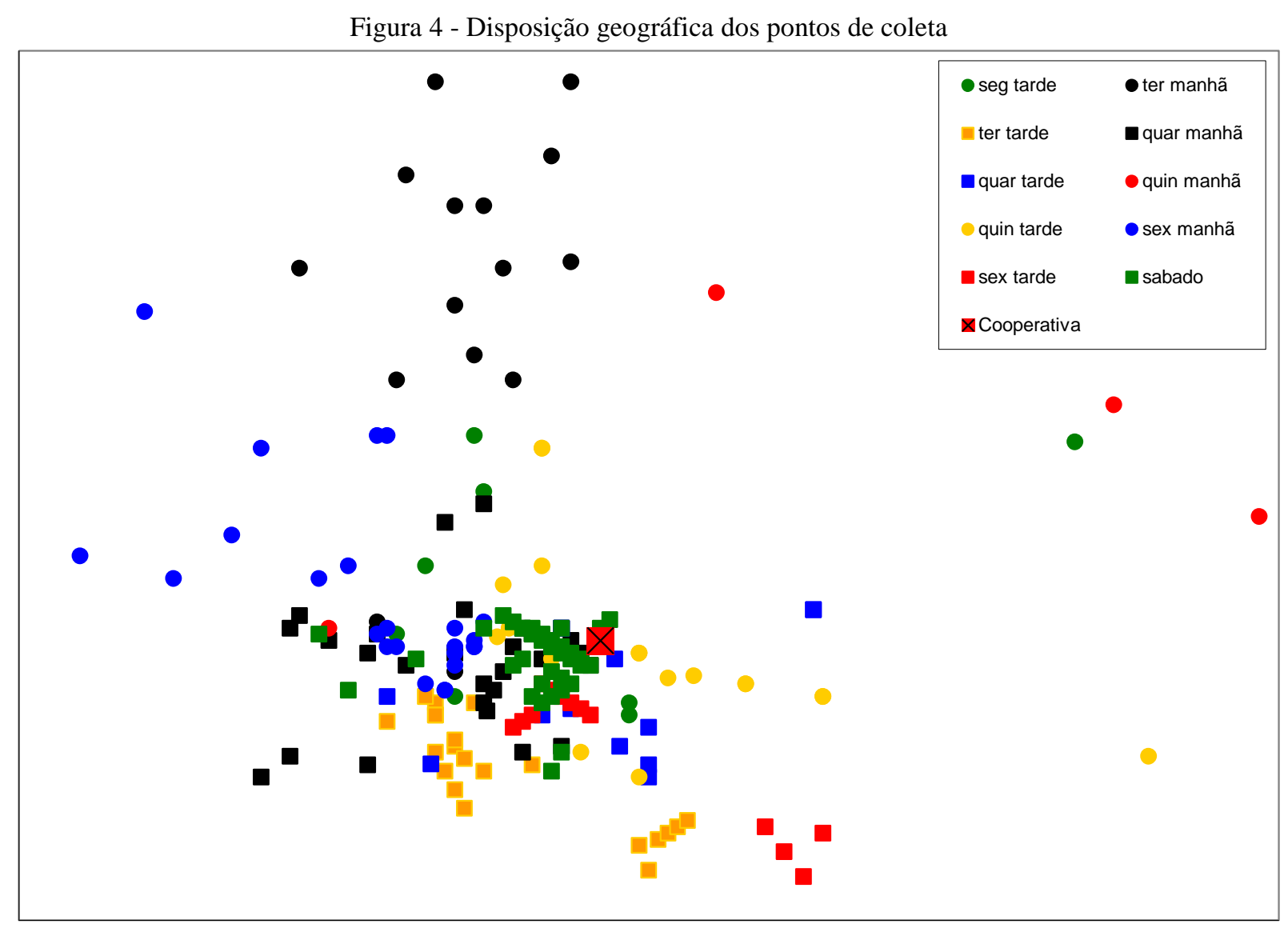

\section{3. $O$ custo do caminhão}

O próximo passo foi conhecer o quanto custa o caminhão utilizado por esta cooperativa popular para fazer as coletas. Utilizando a metodologia proposta por Pimenta Lima e aplicando os dados provenientes do tipo de veículo utilizado pela cooperativa se obtém a Tabela 2 a seguir. 
Tabela 2- Cálculo do custo do veículo usado na coleta de materiais recicláveis

\begin{tabular}{|c|c|c|c|c|c|}
\hline \multicolumn{3}{|l|}{ Dados da Empresa } & \multicolumn{3}{|l|}{ Itens Custo Fixo } \\
\hline Salário do motorista/ajudante & $\mathrm{R} \$ / \mathrm{mês}$ & 2250 & Depreciação & $\mathrm{R} \$ /$ mês & 329,4583333 \\
\hline Hoas de Trabalho no Mês & horas/mês & 176 & Custo de Capital & $\mathrm{R} \$ /$ mês & 754,6911461 \\
\hline Encargos e benefícios & $\mathrm{R} \$ /$ mês & 123,75 & Mão de Obra & $\mathrm{R} \$ / \mathrm{mês}$ & 2769,75 \\
\hline Refeições & $\mathrm{R} \$ /$ mês & 396 & impostos/seguro & $\mathrm{R} \$ /$ mês & 670,29 \\
\hline Taxa de oportunidade & $\% / a n o$ & $12,00 \%$ & Tacógrafo & $\mathrm{R} \$ / \mathrm{mês}$ & 9 \\
\hline Custos Administrativos & $\mathrm{R} \$ / \mathrm{mês}$ & & Lubrificação & $\mathrm{R} \$ /$ mês & 20 \\
\hline & & & Extintor & $\mathrm{R} \$ / \mathrm{mês}$ & 1,25 \\
\hline Dados do Veículo & & & Caixa Ferramenta & $\mathrm{R} \$ /$ mês & 3,333333333 \\
\hline Consumo de Combustível & $\mathrm{Km} / \mathrm{I}$ & 2,8 & & & \\
\hline intervalo de Troca de óleo & $\mathrm{Km}$ & 15000 & TOTAL & & 4557,772813 \\
\hline Litros de Óleo Motor/Carter & litros & 18 & TOTAL por hora & & 25,89643644 \\
\hline Número de Pneus & & 6 & & & \\
\hline Vida útil dos Pneus & $\mathrm{Km}$ & 40000 & Itens Custo Variá & & \\
\hline número de Recapagens & & 2 & Combustível & $\mathrm{R} \$ / \mathrm{Km}$ & 0,682142857 \\
\hline Vida útil da Recapagem & $\mathrm{Km}$ & 20000 & Óleo & $\mathrm{R} \$ / \mathrm{Km}$ & 0,0084 \\
\hline Custos de manutenção & $\mathrm{R} \$ / \mathrm{Km}$ & & pneu & $\mathrm{R} \$ / \mathrm{Km}$ & 0,09223275 \\
\hline número de Lubrificações & ao ano & 4 & Filtros & $\mathrm{R} \$ / \mathrm{Km}$ & 0,012 \\
\hline intervalo alinh./balanc./rodizio & $\mathrm{Km}$ & 10000 & Filtro Freio & $\mathrm{R} \$ / \mathrm{Km}$ & 0,0036 \\
\hline duração do refil tacógrafo & semanas & 10 & & & \\
\hline Intervalo troca Filtro Freio & $\mathrm{Km}$ & 50000 & TOTAL por Km & & 0,798375607 \\
\hline \multicolumn{6}{|l|}{ Dados de mercado } \\
\hline Valor de Aquisição do Veículo & $\mathrm{R} \$$ & 69000 & TOTAL por hora & & 25,90 \\
\hline Valor de Aquisição da Gaiola & $\mathrm{R} \$$ & 10535 & TOTAL por Km & & 0,80 \\
\hline Vida Útil do Veículo & mês & 120 & & & \\
\hline Valor Residual do Veículo & $\mathrm{R} \$$ & 35000 & & & \\
\hline Valor da Gaiola Usada & $\mathrm{R} \$$ & 5000 & & & \\
\hline Preço do óleo & $\mathrm{R} \$ /$ litro & 7 & & & \\
\hline Preço dos Filtros & $\mathrm{R} \$$ & 180 & & & \\
\hline Preço do Pneu & $\mathrm{R} \$$ & 709,77 & & & \\
\hline Preço do Combustível & $\mathrm{R} \$ /$ litro & 1,91 & & & \\
\hline Preço da Recapagem & $\mathrm{R} \$$ & 260 & & & \\
\hline IPVA/DPVAT/licenciamento & $\mathrm{R} \$$ /ano & 1155,6 & & & \\
\hline Seguro do Veículo & $\mathrm{R} \$$ /ano & 6887,88 & & & \\
\hline Custo da Lubrificação & $\mathrm{R} \$$ & 60 & & & \\
\hline Custo Alinh./Balanc./Rodizio & $\mathrm{Km}$ & & & & \\
\hline Custo Filtro Freio & $\mathrm{R} \$$ & 180 & & & \\
\hline Extintor de incendio & $\mathrm{R} \$$ & 15 & & & \\
\hline Caixa de Ferramentas & $\mathrm{R} \$$ & 40 & & & \\
\hline
\end{tabular}

\subsection{A viabilidade das rotas}

De posse do custo fixo e do custo variável do veículo e também sabendo qual a distância percorrida, o peso coletado e o tempo demorado por cada rota, foi possível elaborar uma tabela comparativa onde, para cada rota, foi calculado o qual foi o custo total e o valor do material coletado. Para calcular o valor do material coletado foi utilizado o valor médio de $\mathrm{R} \$ 0,442$ por quilo de material e também se aplicou um fator de 0,85 para descontar $15 \%$ de dejeto comumente encontrado no material coletado. A Tabela 3 apresenta os resultados das rotas de coleta estudas na cooperativa popular de coleta e seleção de recicláveis. 
Tabela 3 - Viabilidade econômica das rotas de coleta de material recicláveis

\begin{tabular}{|l|c|c|c|c|c|}
\hline ROTA & \$ FIXO & \$ VAR & \$ Total & \$ Coletado & $\%$ \\
\hline Quinta M & 151,00 & 36,53 & 187,53 & 1005,11 & $18,66 \%$ \\
Segunda T & 90,64 & 19,96 & 110,60 & 443,33 & $24,95 \%$ \\
Terça T & 84,18 & 16,27 & 100,44 & 393,23 & $25,54 \%$ \\
Sábado & 113,96 & 13,80 & 127,76 & 493,11 & $25,91 \%$ \\
Quarta M & 142,45 & 21,16 & 163,61 & 619,91 & $26,39 \%$ \\
Segunda M & 127,75 & 59,28 & 187,03 & 694,16 & $26,94 \%$ \\
Sexta M & 151,77 & 22,13 & 173,91 & 613,64 & $28,34 \%$ \\
Sexta T & 85,73 & 13,33 & 99,06 & 303,06 & $32,69 \%$ \\
Quarta T & 84,18 & 18,56 & 102,74 & 299,62 & $34,29 \%$ \\
Terça M & 142,45 & 37,60 & 180,05 & 519,72 & $34,64 \%$ \\
Quinta T & 93,24 & 22,93 & 116,17 & 252,97 & $45,92 \%$ \\
\hline
\end{tabular}

Por fim, foi feito o cálculo do percentual que o custo de se fazer a coleta representa sobre o valor do material coletado. Para a rota mais rentável, o custo de se fazer a coleta representa 18,66\% do valor do material coletado, ao passo que, na rota menos rentável o custo de se fazer a coleta representa quase $46 \%$ do valor do material coletado.

Por decisão da cooperativa, todas as rotas que tiveram o percentual de custo superior a $30 \%$ do valor coletado serão repensadas de modo a aumentar a rentabilidade destas rotas.

\subsection{Definindo novas rotas}

A partir da definição de que as rotas que tiveram o percentual de custo superior a $30 \%$ do valor coletado serão repensadas de modo a aumentar a rentabilidade destas rotas, foi feito um estudo para definir novas rotas para estes dias.

Utilizando o software LogWare que acompanha a obra do Ronald Ballou (2006) onde se tem um módulo chamado ROUTESEQ que calcula a seqüência de pontos a serem visitados por um veículo através do problema de caixeiro viajante, foi feito para o roteiro realizado na tarde de quinta-feira uma comparação com a situação atual e com a solução ótima obtida pelo software LogWare.

Figura 5 - Comparação com a rota atual e a rota ótima sugerida pelo LogWare para quinta-feira a tarde
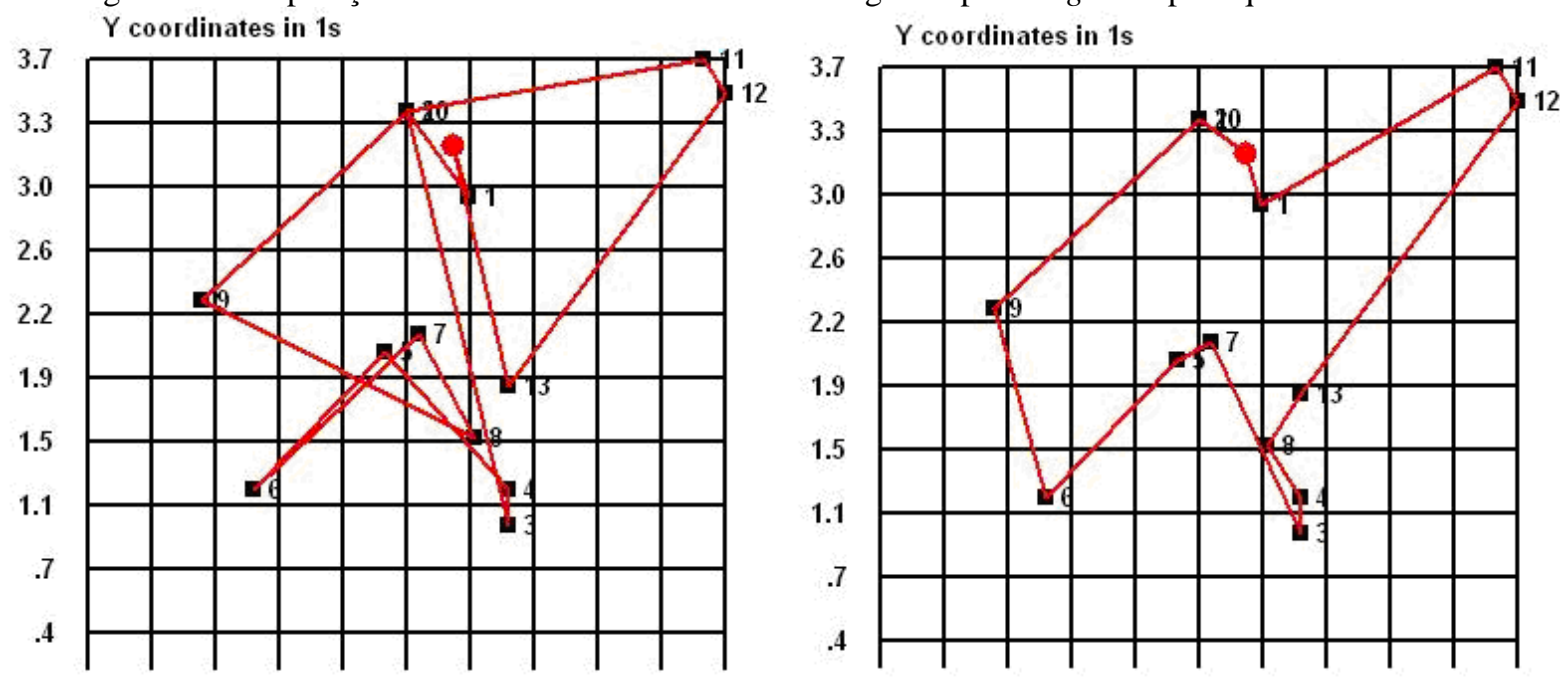
Para alimentar o software LogWare com os dados deste roteiro de coleta foi feito um sistema de coordenadas cartesianas sobre o mapa da cidade de Campinas e, para cada ponto de coleta, foi encontrado a coordenada x e y correspondente e depois inseriu-se estas coordenadas no módulo ROUTESEQ do software LogWare.

A distância total percorrida na rota atual no sistema de coordenadas cartesianas da Figura 5 equivale a uma distância total de 25,006 unidades e a distância total percorrida na solução ótima foi de 16,2 unidades, havendo uma economia de $35,21 \%$ em relação a rota atual.

Procedendo de modo análogo ao roteiro da tarde de quinta-feira para os roteiros para a tarde de quarta-feira e para a manhã de terça-feira obtém-se uma redução de 19,90\% na distância percorrida no roteiro da manhã de terça-feira quando se compara a solução ótima fornecida pelo LogWare em comparação ao roteiro atual (Figura 4).

E para o roteiro de coleta da tarde de quarta-feira obtém-se uma redução de $36,48 \%$ na distância percorrida quando se compara o roteiro atual com a solução ótima fornecida pelo software LogWare.

A visualização dos roteiros atuais e ótimos para a manhã de terça-feira pode ser visto na Figura 6 a seguir e a Figura 7 a seguir mostra a diferença entre o roteiro atual e ótimo para a tarde de quarta-feira.

Figura 6 - Comparação entre a rota atual e a rota ótima para terça-feira de manhã
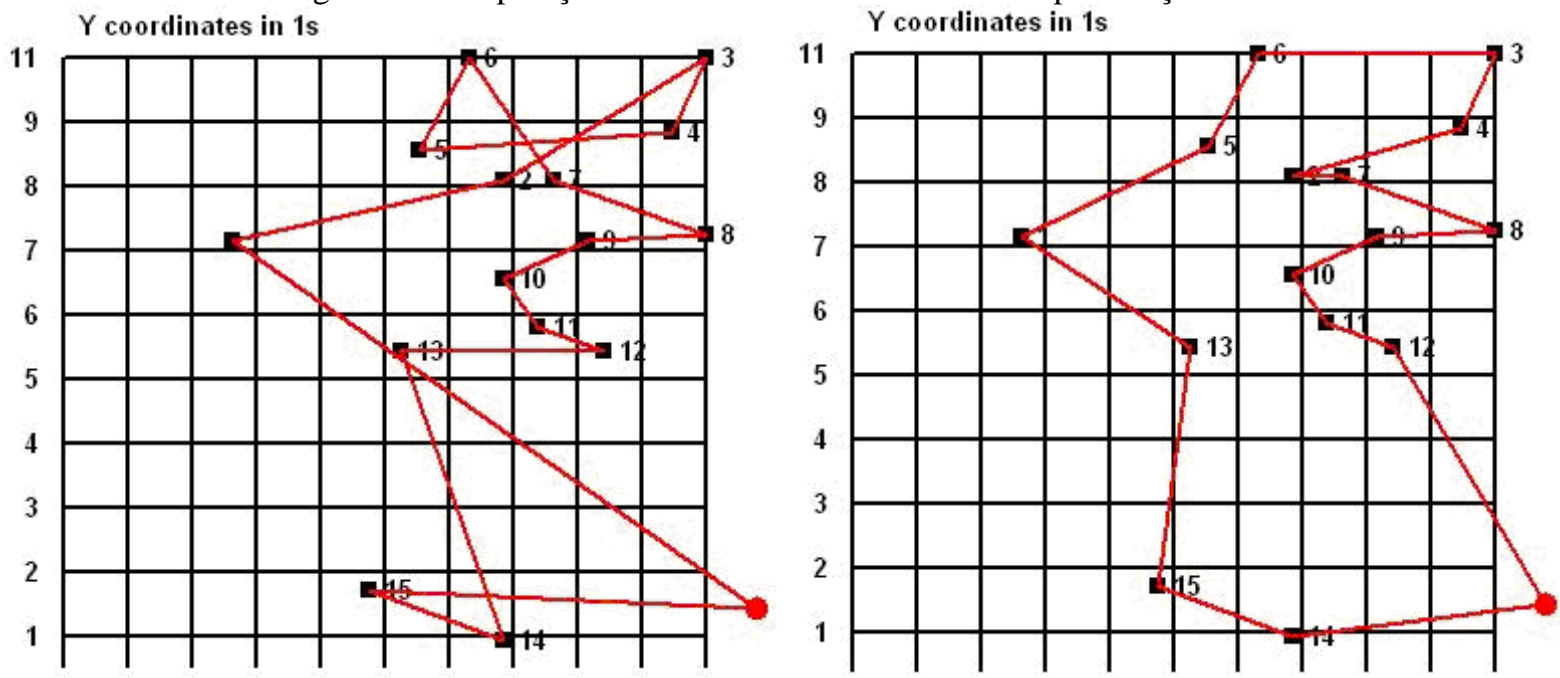


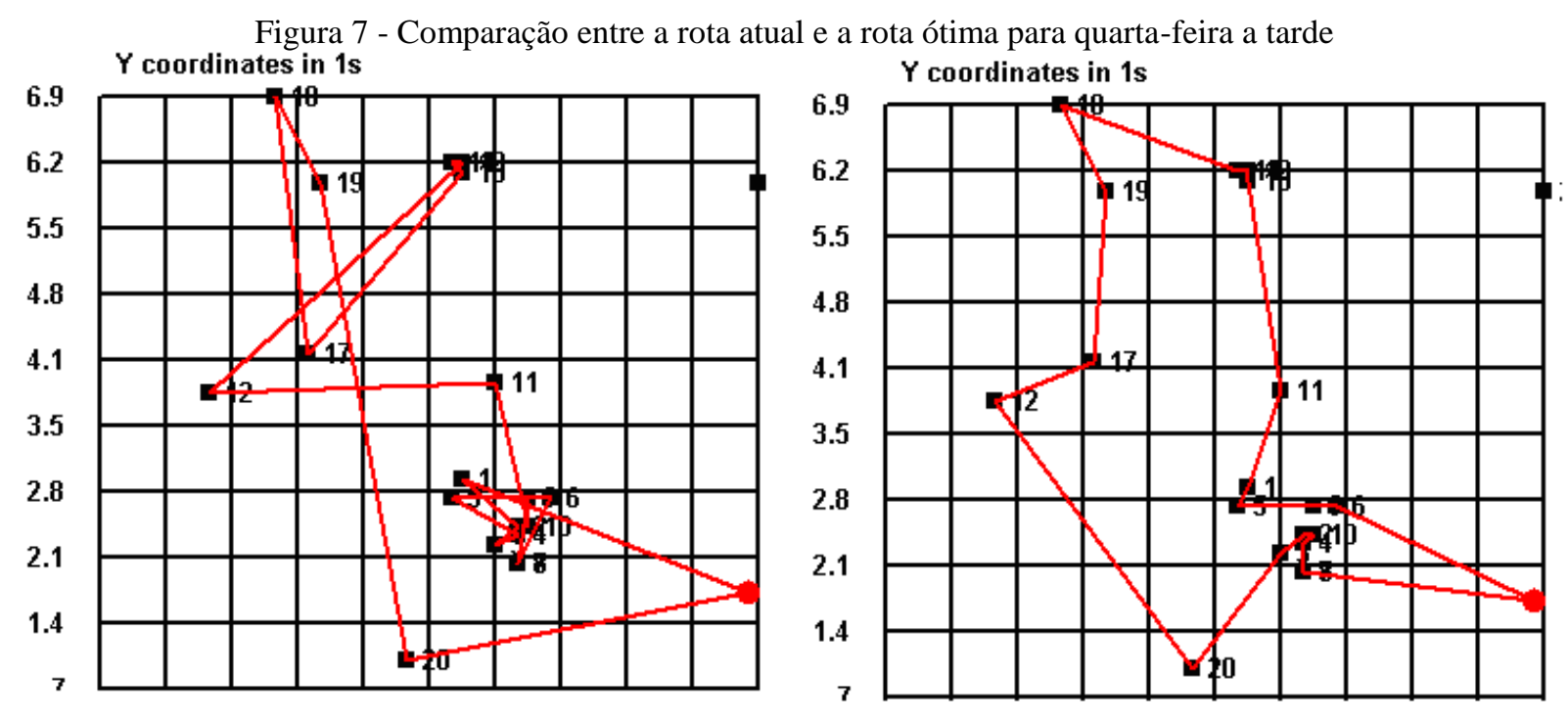

A partir do percentual de redução da distância percorrida com a solução ótima comparada com a solução atual, foi feito a atualização dos custos fixos, dos custos variáveis e da eficiência das rotas da tarde de quarta-feira, da manhã de terça-feira e da tarde de quinta-feira. A Tabela 4 apresenta os custos fixos, variáveis e a eficiência para as soluções ótimas destes dias.

Tabela 4 - Viabilidade econômica para as rotas ótimas

\begin{tabular}{|c|c|c|c|c|c|c|}
\hline \multirow{2}{*}{ ROTA } & \multirow{2}{*}{ \$ FIXO } & \multirow{2}{*}{ \$ VAR } & \multirow{2}{*}{ \$ Total } & \multirow{2}{*}{ \$ Coletado } & \multicolumn{2}{|c|}{ Eficiencia } \\
\cline { 5 - 7 } & & & & & Rota ótima & Rota atual \\
\hline Quarta T & 53.5 & 11.8 & 65.3 & 299.6 & $21.78 \%$ & $34.29 \%$ \\
\hline Terça M & 114.1 & 30.1 & 144.2 & 519.7 & $27.75 \%$ & $34.64 \%$ \\
\hline Quinta T & 60.4 & 14.9 & 75.3 & 253.0 & $29.75 \%$ & $45.92 \%$ \\
\hline
\end{tabular}

\section{Conclusões}

Este estudo forneceu a cooperativa popular que realiza por meios próprios a coleta de mais de $80 \%$ dos materiais que recebe uma visão mais crítica e pragmática da função logística.

Esta visão evidenciou quais rotas estão pouco viáveis, necessitando de uma reformulação nestas rotas, seja pela busca de novas fontes de suprimentos próximas que possa aumentar a quantidade sem onerar muito a distância e o tempo gasto, ou então, na divisão ou fusão de rotas que possam produzir um resultado mais viável que as rotas atuais.

Mais além, este estudo mostrou que um caminhão mesmo parado, custa dinheiro. Esta informação gerou maior atenção por parte do motorista que passou a evitar desperdícios de tempo em manobras e no carregamento e descarregamento dos materiais. Também forneceu a cooperativa elementos que permite a cooperativa decidir se faz ou não a coleta esporádica num determinado ponto. A partir de informações como a distância e o volume a ser coletado é possível saber antecipadamente se compensará ou não realizar esta coleta esporádica.

Por fim, foi feito o cálculo do percentual que o custo de se fazer a coleta representa sobre o valor do material coletado. Para a rota mais rentável, o custo de se fazer a coleta representa 18,66\% 
do valor do material coletado, ao passo que, na rota menos rentável o custo de se fazer a coleta representa quase $46 \%$ do valor do material coletado.

Por decisão da cooperativa, todas as rotas que tiveram o percentual de custo superior a $30 \%$ do valor coletado serão repensadas e este estudo sugeriu uma nova sequiência para estas rotas de modo a aumentar a rentabilidade sem a necessidade de alterar as datas de coleta nos pontos, o que poderia causar problemas de agendamento nestes pontos.

A busca pela eficiência das rotas de coleta de materiais recicláveis é mais que um mero problema de natureza logística. Para as cooperativas populares de coleta e seleção de recicláveis sobreviver integralmente a partir da coleta própria significa não depender mais do poder público para fornecer material reciclado. Atualmente, na maioria das cooperativas populares os materiais são provenientes da coleta realizada pelo departamento de limpeza urbana, situação pouco confortável dado a freqüência com que o poder publico muda de mãos, trazendo insegurança ás cooperativas.

Portanto, contribuir para perspectiva de se ter uma cooperativa popular que realiza integralmente a coleta por meios próprios dos materiais reciclados e realizar tal coleta de modo economicamente eficiente torna este trabalho gratificante e condizente com os ideais de um mundo sustentável e mais justo socialmente.

\begin{abstract}
This paper presents a study of the routes of collecting recyclable materials by a popular cooperative of recyclable incubated by CRCA (Reference Center and Cooperative Associations) in the city of Campinas. This popular cooperative has a truck that daily performs two routes - one in the morning and another in the afternoon - in search of recyclable materials in approximately 200 companies, condominiums and other establishments designed their recyclables to this popular cooperative. However, the routes traveled by the truck does not show efficient, and, in some cases, long, timeconsuming and low volume of material collected. The study presented in this paper proposes new collection routes with greater economic efficiency compared with previous routes. This study is the comparison of the total cost to perform the itinerary and the amount collected by the truck on this route, determining which routes are the most profitable and which are the least profitable. For the less profitable routes was made a reordering of the collection using the traveling salesman problem and recalculated the returns of these routes. A brief theoretical review of logistics, vehicle routing and details about the calculation of the cost of shipping the complete article.
\end{abstract}

Keywords: business logistics; reverse supply chains; sustainability; collection and selection of recyclable; popular cooperatives; routing.

\title{
Referências
}

BALLOU, RONALD H. - Gerenciamento da Cadeia de Suprimentos: planejamento, organização e logística empresarial. 5aed., Porto Alegre: Bookman, 2006.

BREJON, S.R.C. e BELFIORE, P.P. A Importância do Enfoque Sistêmico para Problemas de Roteirização de Veículos. Revista de Pesquisa e Desenvolvimento em Engenharia de Produção, n. 5, p. 64-86, jun. de 2006. 
CHRISTOPHER, M. - Logística e Gerenciamento da Cadeia de Suprimentos: criando redes que agregam valor. $2^{a}$ ed., Ed. Cengage Learning, São Paulo, 2009.

CUNHA, C.B. Aspectos Práticos da Aplicação de Modelos de Roteirização de Veículos a Problemas Reais, Revista Transportes, vol. 8, n. 2, novembro de 2000.

DIAS, B. - Logística Militar: Berço da Logística Empresarial, 2005. Disponível em: < http://www.guialog.com.br/Y626.htm>. Acesso em: 16 fev. 2009.

EKSIOGLU, B.; VURAL, A.V. \& A.REISMAN - The vehicle routing problem: A taxonomic review. Computers \& Industrial Engineering, vol. 57, n.4, pp.1472-1483, nov. 2009. crossref

EUNOMOTO, L.M. e LIMA, R.S. Análise da distribuição física e roteirização em um atacadista, Revista Produção, vol. 17, n. 1, São Paulo, jan-abr de 2007.

GOLDBARG, M. C.; LUNA, H. P.- Otimização Combinatória e Programação Linear. Ed. Campus, Rio de Janeiro, 2005.

GUGLIELMiNETTI, R. - “Campinas recicla apenas 2\% do lixo, diz comissão”. Correio Popular, 25/11/2009, Campinas, 2009.

KUNRATH, R. D. - Logística Empresarial, 1ª ed. Rio Grande do Sul - Ediouro, 2007.

LIMA, M. P. - O Custeio do Transporte Rodoviáveio - Revista Tecnologística, São Paulo, jan. de 2001.

NAZÁRIO, P.; WANKE, PETER; FLEURY, P.F. O Papel de Transporte na Estratégia Logística, 2000, disponível em <http://www.ilos.com.br > acessado em 27/02/2010.

NOVAES, A. G. - Logística e Gerenciamento da Cadeia de Distribuição. 3ed. Ed. Campus. Rio de Janeiro, 2007.

PILLAC, V; GENDREAU, M.; GUÉRET, C. and ANDRÉS L. MEDAGLIA - A review of dynamic vehicle routing problems, European Journal of Operational Research, vol. 225, n.1, pp. 1-11, fev. 2013. crossref

SOUZA, P.T. Logística Interna Para Empresas Prestadoras de Serviço. 2002. Disponível em:

<http://guialog.com.br/ARTIGO350.htm>. Acesso em: 17/02/2009.

\section{Dados do autor}

Nome completo: Marcos Ricardo Rosa Georges

Filiação institucional: Pontifícia Universidade Católica de Campinas

Departamento: Centro de Economia e Administração

Função ou cargo ocupado: Professor Doutor e Pesquisador institucional

Endereço completo para correspondência (bairro, cidade, estado, país e CEP): Rua Mogi Guaçu, n. 1.119, Chácara da Barra, Campinas, CEP 13090-605, SP, Brasil.

Telefones para contato: (19) 97111573

e-mail: marcos.georges@puc-campinas.edu.br, marcos.georges@ hotmail.com

Submetido em: 03/04/2013

Aceito em: 17/09/2014 